\title{
LEMBAR KERJA SISWA BERBASIS SAINTIFIK PADA KONSEP HUKUM OHM UNTUK PEMBELAJARAN FISIKA DI SEKOLAH MENENGAH ATAS
}

\author{
Hikmawati \\ Program Studi Pendidikan Fisika, FKIP Universitas Mataram \\ Email: hikmawati.fisika@yahoo.com
}

\begin{abstract}
Abstrak: Tulisan ini bertujuan untuk mendeskripsikan lembar kerja siswa berbasis saintifik pada konsep Hukum Ohm untuk pembelajaran fisika di Sekolah Menengah Atas. Lembar kerja siswa merupakan panduan siswa yang digunakan untuk melakukan kegiatan penyelidikan atau pemecahan masalah sehingga mempermudah siswa dalam pelaksanaan kegiatan pembelajaran. Lembar kerja siswa berbasis saintifik dapat membantu siswa memperoleh lima pengalaman belajar pokok dalam proses pembelajaran yakni mengamati, menanya, mengumpulkan informasi, mengasosiasi, dan mengkomunikasikan. Komponen-komponen lembar kerja siswa berbasis saintifik pada konsep Hukum Ohm terdiri atas: judul eksperimen, tujuan eksperimen, alat dan bahan, rumusan masalah, hipotesis, variabel, definisi operasional variabel, langkah-langkah eksperimen, data pengamatan, analisis data, dan kesimpulan. Lembar kerja siswa berbasis saintifik diharapkan dapat menjadi salah satu alternatif media untuk mempermudah siswa belajar konsep fisika sehingga tujuan pembelajaran dapat tercapai sesuai yang diinginkan.
\end{abstract}

Kata kunci : lembar kerja siswa, saintifik.

Abstract: This paper aims to describe scientific-based student worksheets on the concept of Ohm's Law for learning physics in senior high school. A student worksheet is used to guide student conduct investigation or problem-solving activities that facilitate students in the implementation of learning activities. Scientific-based student worksheets can help students gain five basic learning experiences in the learning process to observe, ask, gather information, associates, and communicate. The components of scientific-based student worksheets on the concept of Ohm's Law consists of the title of the experiment, the experimental goals, tools and materials, formulation of the problem, hypothesis, variables, operational definitions of variables, steps experimentation, observation data, data analysis, and conclusions. Scientificbased student worksheets expected to be one of the alternative media to facilitate students learn the concepts of physics so that the learning objectives can be achieved as targeted.

Keywords: student worksheets, scientific .

\section{PENDAHULUAN}

Berbagai tantangan yang harus dihadapi dalam dunia pendidikan pada abad 21 ini antara lain berkaitan dengan tantangan masa depan, kompetensi yang diperlukan di masa depan, persepsi masyarakat, perkembangan pengetahuan dan pedagogi, serta berbagai fenomena negatif yang mengemuka. Dalam [1], kompetensi yang diperlukan di masa depan yaitu: kemampuan berkomunikasi, kemampuan berpikir jernih dan kritis, kemampuan mempertimbangkan segi moral suatu permasalahan, kemampuan menjadi warga negara yang bertanggungjawab, kemampuan mencoba untuk mengerti dan toleran terhadap pandangan yang berbeda, kemampuan hidup dalam masyarakat yang mengglobal, memiliki minat luas dalam kehidupan, memiliki kesiapan untuk bekerja, memiliki kecerdasan sesuai dengan bakat/minatnya, memiliki rasa tanggungjawab terhadap lingkungan.

Salah satu upaya pemerintah untuk mencapai kompetensi tersebut di atas adalah dengan melakukan pengembangan kurikulum. Kurikulum 2013 menekankan pada dimensi pedagogik modern dalam pembelajaran, yaitu menggunakan pendekatan ilmiah. Pendekatan ilmiah (scientific approach) dalam pembelajaran sebagaimana dimaksud meliputi mengamati, menanya, menalar, mencoba, membentuk jejaring untuk semua mata pelajaran.
Penerapan pendekatan ilmiah harus menjadi perhatian bagi guru dalam membuat perencanaan pembelajaran. Menurut [2], tugas profesional guru meliputi tiga hal yakni tugas merencanakan pembelajaran, melaksanakan pembelajaran, dan menilai pembelajaran. Tugas-tugas guru dalam dalam perencanaan terdiri atas kemampuan dalam memahami tujuan pembelajaran, melakukan analisis pembelajaran, mengenali perilaku siswa, mengidentifikasi karakteristik siswa, merumuskan tujuan pembelajaran, mengembangkan butir-butir tes, mengembangkan materi pelajaran, mengembangkan media dan metode pembelajaran, menerapkan sumber-sumber pembelajaran, mengkoordinasikan segala faktor pendukung, mengembangkan dan melakukan penilaian awal terhadap rencana pembelajaran, merevisi pembelajaran dan melakukan penilaian akhir terhadap pembelajaran.

Penyusunan perangkat pembelajaran yang baik oleh seorang guru dalam perencanaan pembelajaran tentunya akan berdampak pada meningkatnya kualitas proses pelaksanaan pembelajaran sehingga diharapkan kualitas pendidikan di Indonesia juga akan semakin baik. Menurut [3], komponen perangkat pembelajaran terdiri atas silabus, Rencana Pelaksanaan Pembelajaran (RPP), Buku Ajar Siswa (BAS), media pembelajaran, Lembar Kegiatan Siswa (LKS), dan Instrumen Evaluasi atau Tes Hasil 
Belajar (THB). Tulisan ini akan membahas tentang LKS berbasis saintifik pada konsep Hukum Ohm untuk pembelajaran fisika di SMA.

\section{PEMBAHASAN}

Proses pembelajaran pada Kurikulum 2013 untuk semua jenjang dilaksanakan dengan menggunakan pendekatan ilmiah. Proses pembelajaran harus menyentuh tiga ranah, yaitu sikap, pengetahuan, dan keterampilan. Dalam proses pembelajaran berbasis pendekatan ilmiah, ranah sikap menggamit transformasi substansi atau materi ajar agar peserta didik tahu tentang 'mengapa'. Ranah keterampilan menggamit transformasi substansi atau materi ajar agar peserta didik tahu tentang 'bagaimana'. Ranah pengetahuan menggamit transformasi substansi atau materi ajar agar peserta didik tahu tentang 'apa'.Hasil akhirnya adalah peningkatan dan keseimbangan antara kemampuan untuk menjadi manusia yang baik (soft skills) dan manusia yang memiliki kecakapan dan pengetahuan untuk hidup secara layak (hard skills) dari peserta didik yang meliputi aspek kompetensi sikap, keterampilan, dan pengetahuan. Pendekatan ilmiah (scientific appoach) dalam pembelajaran semua mata pelajaran meliputi menggali informasi melalui pengamatan, bertanya, percobaan, kemudian mengolah data atau informasi, menyajikan data atau informasi, dilanjutkan dengan menganalisis, menalar, kemudian menyimpulkan, dan mencipta [1].

LKS berbasis saintifik dalam proses pembelajaran dapat memberikan lima pengalaman belajar pokok bagi siswa sebagaimana yang tercantum dalam Permendikbud No.81A Tahun 2013 Lampiran IV, yakni: mengamati, menanya, mengumpulkan informasi, mengasosiasi, dan mengkomunikasikan. LKS berbasis saintifik akan menunjang proses terjadinya pembelajaran aktif di kelas. Menurut [4], pembelajaran aktif secara umum didefinisikan sebagai metode pembelajaran yang melibatkan siswa dalam proses pembelajaran. Dengan kata lain, pembelajaran aktif menuntut siswa untuk melakukan kegiatan belajar yang bermakna dan berpikir tentang apa yang mereka lakukan. Penelitian [5] menunjukkan bahwa metode pembelajaran berpusat pada siswa (student-centered methods) menghasilkan hasil belajar siswa yang lebih baik dibandingkan metode tradisional (traditional lecture-based courses).

Menurut [6], LKS merupakan panduan siswa yang digunakan untuk melakukan kegiatan penyelidikan atau pemecahan masalah. LKS dapat berupa panduan untuk latihan pengembangan aspek kognitif maupun panduan untuk pengembangan semua aspek pembelajaran dalam bentuk panduan eksperimen atau demonstrasi. LKS memuat sekumpulan kegiatan mendasar yang harus dilakukan oleh siswa untuk memaksimalkan pemahaman dalam upaya pembentukan kemampuan dasar sesuai indikator pencapaian hasil belajar yang harus ditempuh. Komponen-komponen LKS meliputi: judul eksperimen, teori singkat tentang materi, alat dan

bahan, prosedur eksperimen, data pengamatan serta pertanyaan dan kesimpulan untuk bahan diskusi.

LKS berbasis saintifk pada konsep Hukum Ohm terdiri atas: judul eksperimen, tujuan eksperimen, alat dan bahan, rumusan masalah, hipotesis, variabel, definisi operasional variabel, langkah-langkah eksperimen, data pengamatan, analisis data, dan kesimpulan [7].

Berdasarkan komponen-komponen yang terdapat dalam sebuah LKS, maka seorang guru dapat membuat judul eksperimen yaitu: "Hukum Ohm". Tujuan eksperimen yang diinginkan antara lain: (1) Untuk menyelidiki pengaruh tegangan (V) terhadap arus (I); dan (2) Untuk menyelidiki hubungan antara tegangan (V), arus (I), dan hambatan (R).

Alat dan bahan yang diperlukan untuk melakukan eksperimen Hukum Ohm yakni: 2 buah Multimeter, 3 buah Resistor yang sudah diketahui nilai hambatannya, 1 set baterai $3 \mathrm{~V}, 1$ set baterai $6 \mathrm{~V}$, kabel penghubung, dan sebuah papan eksperimen Hukum Ohm. Berikut ini disajikan tabel alat dan bahan serta kegunaannya.

Tabel 1. Alat dan Bahan Eksperimen Hukum Ohm

\begin{tabular}{|l|l|}
\hline Alat \& Bahan & $\begin{array}{l}\text { Kegunaan } \\
\text { digunakan sebagai } \\
\text { voltmeter (untuk } \\
\text { mengukur tegangan atau } \\
\text { beda potensial) dan } \\
\text { sebagai amperemeter } \\
\text { (untuk mengukur arus). }\end{array}$ \\
\hline Baterai & $\begin{array}{l}\text { digunakan sebagai } \\
\text { sumber tegangan. }\end{array}$ \\
\hline Resistor & $\begin{array}{l}\text { digunakan sebagai } \\
\text { Penghambat arus. }\end{array}$ \\
\hline
\end{tabular}


Rumusan masalah yang dapat dibuat adalah: (1) Bagaimanakah pengaruh tegangan (V) terhadap arus (I)?; (2) Bagaimanakah hubungan antara tegangan (V), arus(I), dan hambatan (R)?. Hipotesis dalam LKS berbasis saintifik berupa jawaban sementara atas rumusan masalah yang telah dibuat. Dalam [8] dikatakan bahwa hipotesis adalah dugaan tentang pengaruh apa yang akan diberikan variabel manipulasi terhadap variabel respon. Hipotesis dirumuskan dalam bentuk pernyataan bukan pertanyaan.

Variabel yang diamati dalam kegiatan eksperimen Hukum Ohm meliputi variabel bebas (manipulasi) dan variabel terikat (respon). Menurut [8], variabel adalah suatu besaran yang dapat bervariasi atau berubah pada suatu situasi tertentu. Dalam mengidentifikasi atau menuliskan variabel harus disebutkan atau dituliskan bagaimana tiap variabel akan diukur.

Langkah-langkah yang dilakukan dalam Hukum Ohm adalah sebagai berikut. Siapkan semua alat dan bahan yang dibutuhkan dalam eksperimen. Rangkai alat dan bahan seperti yang tunjukkan pada gambar di bawah ini.

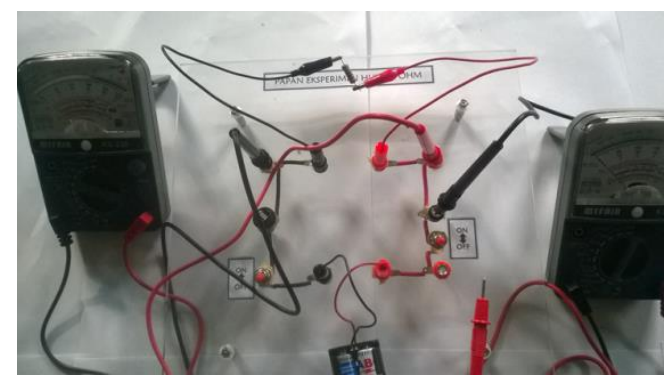

Gunakan resistor dengan nilai yang paling rendah, $\mathrm{R}_{1}=100 \Omega$.

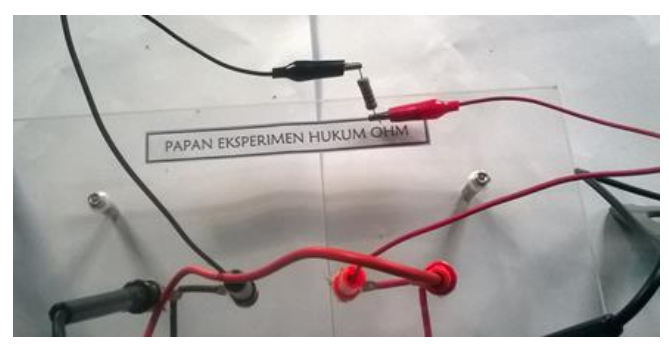

Gunakan 1 set baterai $3 \mathrm{~V}$.

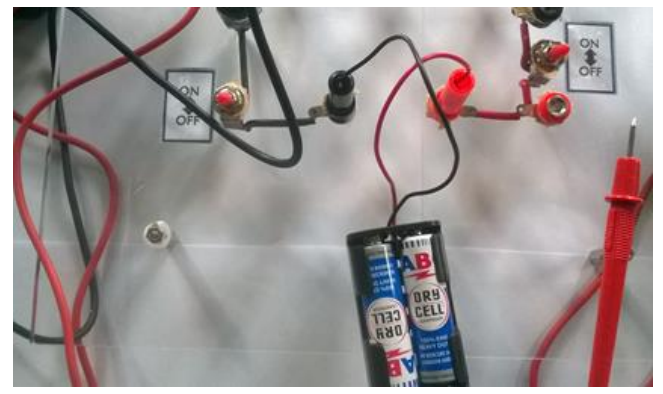

Posisikan RBU untuk pengukuran beda potensial pada posisi $50 \mathrm{DCV}$.

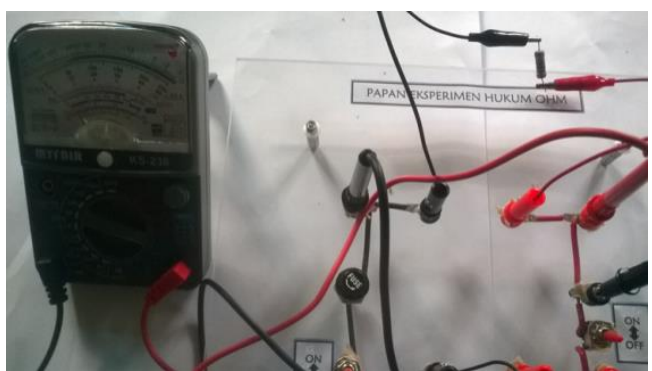

Posisikan RBU untuk pengukuran arus pada 0.5 DCA.

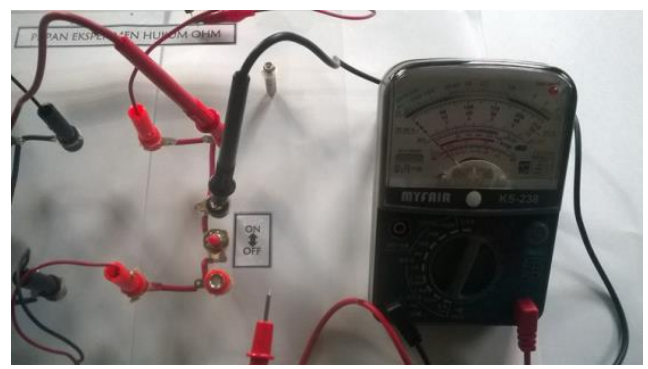

Posisikan saklar sebelah kiri pada posisi ON dan saklar sebelah kanan pada osisi OFF. Bacalah hasil pengukuran terhadap beda potensial dan kuat arus dengan menggunakan metode cara membaca hasil pengukuran seperti pada eksperimen sebelumnya. Pindahkan hasil pengukuran pada tabel yang disiapkan. Ulangi langkah-langkah eksperimen tersebut di atas dengan menggunakan Resistor yang berbeda, yaitu $R_{2}=$ $330 \Omega$ dan $R_{3}=390 \Omega$. Tabel hasil pengukuran dengan Baterai $3 \mathrm{~V}$ dapat dibuat seperti berikut ini.

Tabel 2. Hasil pengukuran dengan Baterai $3 \mathrm{~V}$

\begin{tabular}{|l|c|l|l|}
\hline No. & $\mathbf{R}(\mathbf{\Omega})$ & $\mathbf{V}$ (volt) & I (A) \\
\hline 1 & $100 \Omega$ & & \\
\hline 2 & $330 \Omega$ & & \\
\hline 3 & $390 \Omega$ & & \\
\hline
\end{tabular}

Ulangi langkah-langkah eksperimen tersebut di atas dengan menggunakan 1 set baterai $6 \mathrm{~V}$. Pindahkan hasil pengukuran pada tabel yang disiapkan dalam bentuk seperti berikut ini.

Tabel 3. Hasil Pengukuran Dengan Baterai $6 \mathrm{~V}$

\begin{tabular}{|l|l|l|l|}
\hline No. & $\mathbf{R}(\mathbf{\Omega})$ & $\mathbf{V}($ volt) & I (A) \\
\hline 1 & $100 \Omega$ & & \\
\hline 2 & $330 \Omega$ & & \\
\hline 3 & $390 \Omega$ & & \\
\hline
\end{tabular}

Langkah eksperimen berikutnya adalah membuat grafik hubungan antara tegangan dan arus 
untuk baterai $3 \mathrm{~V}$ dan juga $6 \mathrm{~V}$. Kegiatan analisis data dapat dibantu dengan pertanyaan-pertanyaan sebagai berikut. Hitunglah nilai V/I pada setiap percobaan yang telah kamu lakukan! Bandingkan setiap nilai V/I yang kamu dapatkan dalam perhitungan dengan nilai hambatan (R) lampu yang kamu gunakan dalam rangkaian? Bagaimana hubungan antara V/I dan R? Dari percobaan yang telah kamu lakukan, bagaimana hubungan antara tegangan dan arus? Bagaimanakah hubungan antara tegangan, arus, dan hambatan? Komponen LKS terakhir adalah membuat kesimpulan yang berupa jawaban atas rumusan masalah.

Hasil eksperimen yang dilakukan oleh siswa atau sekelompok siswa dikomunikasikan ke siswa lainnya atau kelompok lain dalam kelas sehingga hasil eksperimen tersebut berperan sebagai bahan diskusi dalam proses pembelajaran. Menurut [8], eksperimen dapat didefinisikan sebagai usaha sistematik yang direncanakan untuk menghasilkan data guna menjawab suatu masalah atau menguji suatu hipotesis. Apabila cara bagaimana suatu variabel akan dimanipulasi dan jenis respon yang diharapkan dinyatakan secara jelas dalam bentuk definisi operasional, maka sebagian besar pekerjaan perencanaan eksperimen sebagai persiapan pengumpuan data telah terselesaikan. Yang tersisa tinggal menetapkan kondisi-kondisi eksperimen lain dalam rangka pengontrolan variabel kontrol.

Eksperimen merupakan upaya menyelidiki suatu objek. Konsep-konsep yang ditemukan memang bukan konsep-konsep fisika yang baru, tujuan eksperimen yang dilakukan siswa tersebut memberikan latihan-latihan tentang pola berpikir dan cara-cara yang biasa ditempuh para ilmuwan dalam menemukan konsep-konsep fisika. Latihan-latihan tersebut diharapkan dapat merangsang kreativitas dalam kehidupan sehari-hari di lingkungan keluarga dan masyarakat [9]. Menurut [10], beberapa proses sains yang perlu dilatihkan kepada siswa di sekolah dasar dan menengah adalah mengamati (observing), mengklasifikasi (classifying), membuat inferensi (inferring), mengukur (measuring), mengkomunikasikan (communicating), memprediksi (predicting), membuat hipotesis (hypothesizing), dan melakukan eksperimen (experimenting). Dalam [11] dikatakan bahwa keterampilan proses sains dalam pembelajaran mengajarkan siswa untuk berpikir kritis tentang ide atau subjek dan memecahkan masalah.

\section{PENUTUP}

Lembar Kerja Siswa (LKS) berbasis saintifik merupakan salah satu alternatif media bagi guru untuk mempermudah siswa mencapai tujuan pembelajaran. LKS berbasis saintifik membantu siswa dalam mengembangkan keterampilan berpikir kritis. Pengalaman belajar yang didapatkan siswa dengan fasilitas LKS berbasis saintifik adalah mengamati, menanya, mengumpulkan informasi, mengasosiasi, dan mengkomunikasikan. Komponen LKS untuk konsep Hukum Ohm di SMA meliputi judul eksperimen, tujuan eksperimen, alat dan bahan, rumusan masalah, hipotesis, variabel, definisi operasional variabel, langkah-langkah eksperimen, data pengamatan, analisis data, dan kesimpulan.

\section{DAFTAR PUSTAKA}

[1]. Kemendikbud. 2013. Materi Pelatihan Guru: Implementasi Kurikulum 2013 SMP/MTs Ilmu Pengetahuan Alam. Jakarta: Badan Pengembangan Sumber Daya Manusia Pendidikan dan Kebudayaan dan Penjaminan Mutu Pendidikan.

[2]. Rusman. 2012. Belajar dan Pembelajaran Berbasis Komputer: Mengembangkan Profesionalisme Abad 21. Bandung: Alfabeta.

[3]. Ibrahim, M. 2003. Pengembangan Perangkat Pembelajaran (Pelatihan Terintegrasi Berbasis Kompetensi Guru Mata Pelajaran Biologi). Surabaya: Depdiknas.

[4]. Prince, M. 2004. Does Active Learning Work? A Review of the Research. Journal of Engineering Education, 93(3), 223-231.

[5]. Stephanie V. Chasteen, Steven J. Pollock, Rachel E. Pepper and Katherine K. Perkins. 2012. Thinking like a physicist: A multisemester case study of junior-level electricity and magnetism. American Journal of Physics, 80, 923 (2012).

[6]. Trianto. 2008. Mendesain Pembelajaran Kontekstual (Contextual Teaching and Learning) di Kelas. Jakarta: Cerdas Pustaka Publisher.

[7]. Hikmawati, Rokhmat, J., dan Sutrio. 2015. Pengembangan Perangkat Pembelajaran Fisika dengan Pendekatan Saintifik dan Model Siklus Belajar 5E Sebagai Upaya Meningkatkan Kecakapan Hidup Siswa MA di KKM 2 Lombok Barat. Laporan Penelitian Hibah Bersaing. Mataram: Universitas Mataram.

[8]. Nur, Mohamad. 1997. Eksperimen (Lembar Kegiatan Siswa). Jakarta: Dirjendikdasmen.

[9]. Cholid, Ali Ofid. 2013. Terobosan Baru...!!! Panduan Lengkap Praktikum Fisika SMA Kelas X, XI, dan XII. Yogyakarta: Pustaka Widyatama.

[10]. Bass, J. E., Contant, T. L., and Carin, A. A. 2009. Teaching Science as Inquiry. United States of America: Pearson/Allyin \& Bacon.

[11]. Myers, E. 2006. A Personal Study Of Science Process Skills In A General Physics Classroom. Saint Paul, Minnesota: Hamline University. 